\title{
Trajectory and Aeroheating Environment Development and Sensitivity Analysis for Capsule-Shaped Vehicles
}

\author{
Jeffrey S. Robinson ${ }^{*}$ and Kathryn E. Wurster ${ }^{\dagger}$ \\ NASA Langley Research Center, Hampton, VA, 23430
}

\begin{abstract}
Recently, NASA's Exploration Systems Research and Technology Project funded several tasks that endeavored to develop and evaluate various thermal protection systems and high temperature material concepts for potential use on the crew exploration vehicle. In support of these tasks, NASA Langley's Vehicle Analysis Branch generated trajectory information and associated aeroheating environments for more than 60 unique entry cases. Using the Apollo Command Module as the baseline entry system because of its relevance to the favored crew exploration vehicle design, trajectories for a range of lunar and Mars return, direct and aerocapture Earth-entry scenarios were developed. For direct entry, a matrix of cases was created that reflects reasonably expected minimum and maximum values of vehicle ballistic coefficient, inertial velocity at entry interface, and inertial flight path angle at entry interface. For aerocapture, trajectories were generated for a range of values of initial velocity and ballistic coefficient that, when combined with proper initial flight path angles, resulted in achieving a low Earth orbit either by employing a full lift vector up or full lift vector down attitude. For each trajectory generated, aeroheating environments were generated which were intended to bound the thermal protection system requirements for likely crew exploration vehicle concepts. The trades examined clearly pointed to a range of missions / concepts that will require ablative systems as well as a range for which reusable systems may be feasible. In addition, the results clearly indicated those entry conditions and modes suitable for manned flight, considering vehicle deceleration levels experienced during entry. This paper presents an overview of the analysis performed, including the assumptions, methods, and general approach used, as well as a summary of the trajectory and aerothermal environment information that was generated.
\end{abstract}

\section{Nomenclature}

$\begin{array}{ll}\text { CEV } & =\text { crew exploration vehicle } \\ \mathrm{C}_{\mathrm{D}} & =\text { drag coefficient } \\ \mathrm{C}_{\mathrm{L}} & =\text { lift coefficient } \\ \mathrm{CM} & =\text { command module } \\ \mathrm{ESR} \& \mathrm{~T} & =\text { Exploration Systems Research \& Technology } \\ \mathrm{GEO} & =\text { Geosynchronous Earth Orbit } \\ \mathrm{LEO} & =\text { Low Earth Orbit } \\ \text { POST2 } & =\text { Program to Optimize Simulated Trajectories II } \\ \mathrm{TPS} & =\text { thermal protection system } \\ \mathrm{VAB} & =\text { Vehicle Analysis Branch }\end{array}$

\section{Introduction}

In response to the President's 2004 announcement of the Vision for Space Exploration (VSE) ${ }^{1}$, NASA's Exploration Systems Research and Technology (ESR\&T) Project funded several tasks in 2005 that endeavored to develop and evaluate various thermal protection systems (TPS) and high temperature material concepts for potential use on the Crew Exploration Vehicle (CEV), the system that will carry astronauts back to the moon. NASA

\footnotetext{
* Engineer, Vehicle Analysis Branch, M/S 451, AIAA Senior Member.

${ }^{\dagger}$ Engineer, Vehicle Analysis Branch, M/S 451, AIAA Associate Fellow.
} 
Langley's Vehicle Analysis Branch (VAB) supported several of these tasks by providing trajectory and associated aerothermal environments for a multitude of Earth re-entry scenarios. Specifically, VAB supported the Lightweight Nonmetallic Thermal Protection Materials Technology Project, a multi-center Thermal Protection System (TPS) working group, and Integrated Thermal Protection Systems and Heat Resistant Structures, an ESR\&T external task conducted by a multi-national group of engineering organizations. This paper provides a description of the assumptions, methods, and general approach used to generate the Earth entry environment information, as well as a sampling of some of the results.

Missions considered at the outset of the project included manned and robotic missions, to and from: LEO, GEO, the moon, and Mars, as well as extended planetary missions. The approach to mission selection took into consideration two key issues: first, since the decision to retire the Shuttle has already been made, what is the most likely next step for NASA's exploration programs, and second, what are the most significant challenges in terms of human-rating materials/concepts to support these programs? In and of itself, the necessity to human-rate the materials and concepts presents one of the greatest challenges. While the robotic missions generally must withstand much more severe space environments, particularly in terms of trip time, the consequence of failure of an unmanned mission was deemed much less damaging to the future of exploration. The decision was made to focus more on the atmospheric entry environments and to concentrate more on manned mission requirements.

At the time this work was performed, little definition existed for the VSE and its associated space exploration architecture. Various exploration architecture studies were under way and were reviewed, as were the industry proposed concepts for the CEV. For this work, the Apollo Command Module ${ }^{2}$, shown in Figure 1 , was selected as the baseline entry system because of its apparent relevance to several CEV concepts currently under consideration together with the availability of an extensive database. In order to adequately cover the potential design space, this study examined a range of direct and aerocapture Earth re-entry trajectories from lunar and Mars return conditions, as well as entries from low Earth orbit. Potential alternate concepts / architectures were represented by a matrix of offnominal trajectory profiles generated for an expected range of entry velocities, flight-path angles and vehicle ballistic coefficients defining the likely mission trade space.

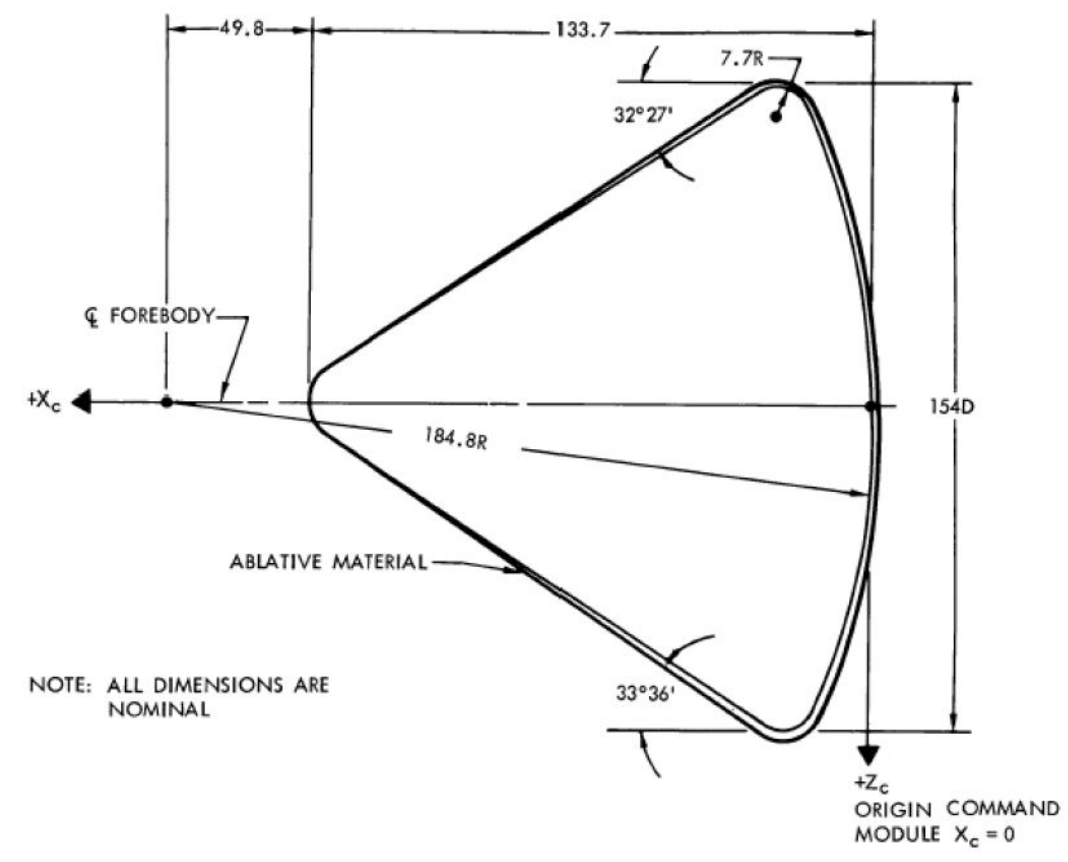

Figure 1. Apollo Command Module (CM) geometry.

\section{Trajectory Analysis}

Trajectory analysis was performed using the Program to Optimize Simulated Trajectories II (POST2) code ${ }^{3}$. Each trajectory was run with three degrees of freedom (3-DoF) using the 1976 Standard Atmosphere model (no winds) and with a rotating WGS-84 oblate earth model. The vehicle was commanded to follow the angle of attack profile shown in Table 1. Output data was captured starting at 121,920 m (which is near the beginning of sensible atmosphere / start of heating). Landing location (latitude and longitude) were not considered during this study.

For the direct entries, one nominal case was developed each for lunar and Mars returns in addition to a matrix of off-nominal cases for each. These matrices of cases reflect reasonably expected minimum and maximum values of vehicle ballistic coefficient, inertial velocity at entry interface, and inertial flight path angle at entry interface. For the aerocapture cases, three velocities and three ballistic coefficients (expected high, nominal, and low values) were used along with initial flight path angles that resulted in achieving a low Earth orbit by employing a full lift vector up or full lift vector down attitude. Aeroheating environments were generated for all trajectory cases and were 
intended to bound the TPS thermal requirements for likely CEV concepts. For reference, the aerodynamic characteristics of the Apollo $\mathrm{CM}^{4}$ are shown in Table 1. The aerodynamic reference area is 12.017 $\mathrm{m}^{2}$, based upon the diameter of the heat shield, and the nominal mass for the CM used in the trajectory simulations was $5500 \mathrm{~kg}$.

The flight path angle and velocity for the nominal lunar return (case 0) were determined from Apollo lunar mission

\begin{tabular}{|c|c|c|c|c|c|}
\hline $\begin{array}{c}\text { Mach } \\
()\end{array}$ & $\begin{array}{c}\text { Angle of } \\
\text { Attack } \\
(\mathrm{deg})\end{array}$ & $\begin{array}{l}\mathrm{C}_{\mathrm{L}} \\
(\mathrm{)}\end{array}$ & $\begin{array}{l}C_{D} \\
()\end{array}$ & $\begin{array}{c}\text { Lift/Drag } \\
()\end{array}$ & $\begin{array}{c}\text { Ballistic } \\
\text { Coefficient } \\
\left(\mathrm{kg} / \mathrm{m}^{\wedge} 2\right)\end{array}$ \\
\hline 0.4 & 167.14 & 0.24465 & 0.85300 & 0.28682 & 537.39 \\
\hline 0.7 & 164.38 & 0.26325 & 0.98542 & 0.26714 & 465.16 \\
\hline 0.9 & 161.70 & 0.32074 & 1.10652 & 0.30110 & 414.26 \\
\hline 1.1 & 154.87 & 0.49373 & 1.16970 & 0.42208 & 391.86 \\
\hline 1.2 & 155.13 & 0.47853 & 1.15600 & 0.41395 & 396.50 \\
\hline 1.35 & 154.01 & 0.56282 & 1.27880 & 0.44013 & 358.44 \\
\hline 1.65 & 153.22 & 0.55002 & 1.26570 & 0.43455 & 362.14 \\
\hline 2.0 & 153.14 & 0.53247 & 1.27210 & 0.41858 & 360.34 \\
\hline 2.4 & 153.62 & 0.50740 & 1.24120 & 0.40881 & 369.32 \\
\hline 3.0 & 154.14 & 0.47883 & 1.21670 & 0.39353 & 376.74 \\
\hline 4.0 & 156.12 & 0.44147 & 1.21480 & 0.36340 & 377.32 \\
\hline 10.0 & 156.79 & 0.42856 & 1.22460 & 0.34996 & 374.30 \\
\hline$\geq 29.5$ & 160.06 & 0.38773 & 1.28910 & 0.30076 & 355.61 \\
\hline
\end{tabular}

Table 1. Lift and drag coefficients, trim angle of attack, L/D, and ballistic coefficient as a function of Mach number for the Apollo CM

data $^{5}$. The range of initial off-nominal velocities was selected based upon experience and previous work (examination of actual Apollo entry trajectories and recent lunar abort analysis). Similar information was used to determine the nominal and off-nominal velocities for the Mars return cases. As mentioned, ballistic coefficients were selected to cover a range of potential entry concepts, including capsules and aerodynamic decelerator concepts. Ballistic coefficients were achieved by altering the vehicle mass, keeping the reference area (and therefore the aerodynamics) the same. For the direct entry cases (both lunar and Mars return), the minimum and maximum allowable flight path angles were determined for each combination of velocity and ballistic coefficient under the constraints of a maximum total acceleration of $10 \mathrm{~g}$ 's and a maximum skip-out altitude of $121,920 \mathrm{~m}$. The only exception was for cases 7 and 8 of the direct return from Mars, where the acceleration limit was relaxed to 12 g's to allow some spread between min and max flight path angle. POST2 was allowed to modulate bank angle, thereby redirecting the lift vector, to help optimize each case. For the aerocapture cases, the flight path angle for each combination of velocity and ballistic coefficient was determined by flying the vehicle either full lift vector up or full lift vector down and targeting a $500 \mathrm{~km}$ apogee orbit.

\section{Aeroheating Analysis}

Aerothermal environments were generated for two critical stations on the forebody heat shield, the stagnation area and the "hot" corner, i.e. the corner of the heat shield facing into the flow when the vehicle is at angle of attack. Figure 2 illustrates a representative Apollo CM heating distribution along the symmetry plane, highlighting the stagnation point and the "hot" corner locations. Timedependent environments for these locations were generated for each trajectory. Relevant thermal data, which have been benchmarked where possible to flight, wind-tunnel and/ or detailed computational solutions, were integrated using the aeroheating design code MINIVER $^{6}$, which was also used to predict the thermal environments for all missions examined. Established engineering techniques were used to predict both the convective $^{7}$ and radiative ${ }^{8}$ components of the incident heating environments at the stagnation point. The technique used for the convective heating has been extensively validated against flight, wind-tunnel, and computational data. The radiative prediction correlation used for the stagnation area was derived from an extensive set of detailed computational solutions and has been previously validated for Apollo-like configurations. The

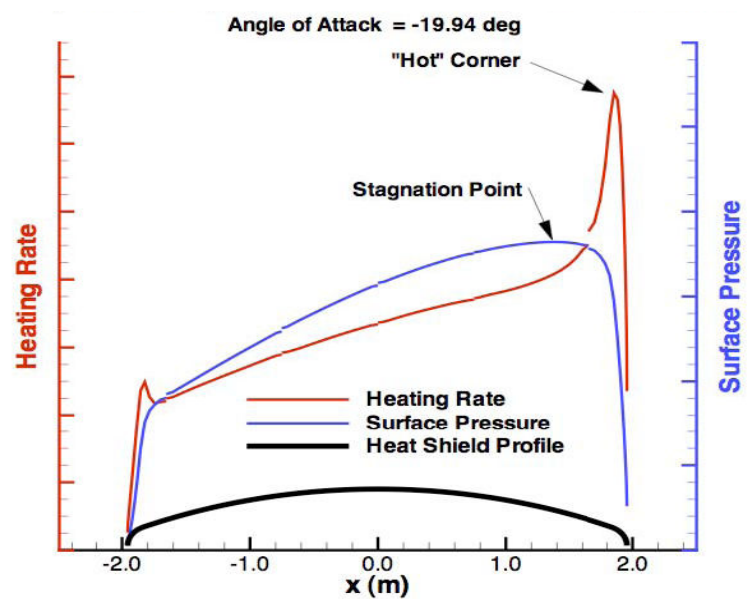

Figure 2. Apollo forebody symmetry plane heating and pressure profile at angle of attack. 
engineering solutions utilized an effective nose radius approach for both the convective and the radiative components. The effective radius was selected to match the velocity gradient (convective) and the shock-standoff distance (radiative) for the Apollo configuration at the same condition. The convective radius was selected based on the Apollo CM geometry together with data from Zoby and Sullivan ${ }^{9}$, originally derived for the zero-degree angle of attack case. An angle of attack of $\sim 20$ deg would be expected to decrease that effective radius, suggesting that the convective results presented here are non-conservative. The effective radius for the radiative component was determined from Reid ${ }^{10}$, which was based on early Apollo studies. The heating at the "hot" corner was determined as a ratio to the stagnation or reference level, based on available heating distributions for Apollo, or Apollo-like concepts (wind-tunnel distributions for convective and distributions available in the literature for radiative).

Radiative heating effects were presumed to be negligible below approximately $9 \mathrm{~km} / \mathrm{sec}$. The relative levels of radiative heating and convective heating are strongly dependent on the flight profile. While the radiative component increases with both velocity and vehicle size, convective heating increases with velocity, but generally decreases with increased vehicle size. These affects are illustrated in Figures 3 and 4 for nominal lunar and Mars return conditions. The flight profile in turn is strongly influenced by the vehicle's ballistic coefficient, initial flight path angle and entry velocity. It should be noted that the convective heating methodology employed will likely break down at the higher entry velocities. However, the radiative contribution tends to dominate the total heating for the high-velocity aerocapture and direct return conditions (for all except the low ballistic coefficient cases). The entry velocities for return from Earth orbit are well within the range of applicability of the convective approach utilized. Thus, this limitation should not influence the conclusions that can be drawn from these data with respect to the applicability of potential material concepts.

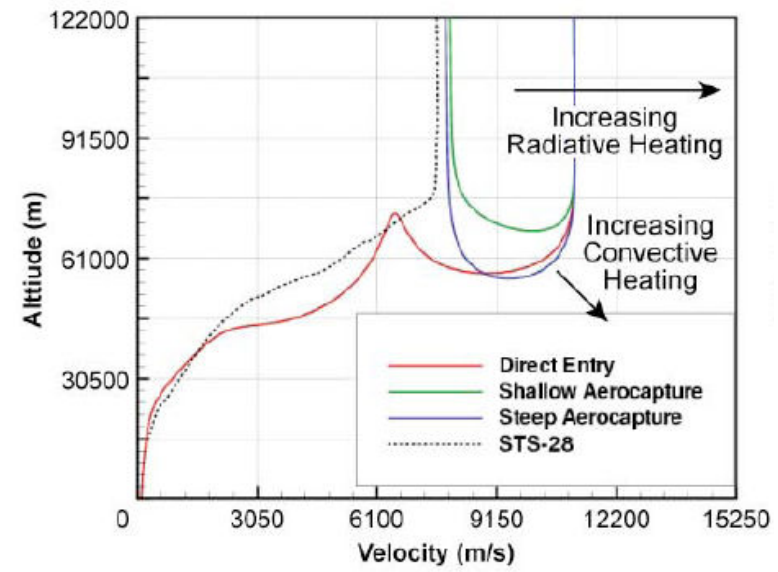

Figure 3. Typical lunar return trajectories showing areas of increased convective and readiative heating.

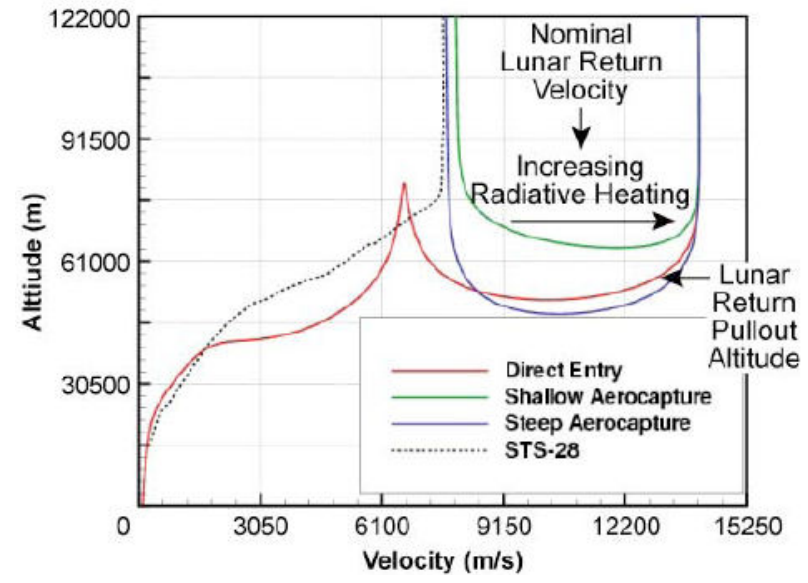

Figure 4. Typical Mars return trajectories showing areas of increased convective and readiative heating.

All aeroheating environments were generated using the 1976 Standard Atmosphere model. Freestream conditions may deviate very slightly from the 1976 standard, based on the curve fit used to reduce the input profile to 500 or fewer points as required by the MINIVER code. Both convective and radiative heating are assumed to be dominated by equilibrium flow. Non-equilibrium and turbulent heating effects were ignored. The extremely high heating levels occurring early in the entries at higher altitudes are expected to outweigh the impact of turbulence which is likely to occur after the peak heating condition. For an Apollo-like configuration, turbulence will generally occur over the "leeward" side of the front face, near the "cooler" corner. It is assumed that the laminar heating levels at the "hot" corner will exceed the turbulent levels at the "cooler" corner as will the loads. Thus a TPS designed for the "hot" corner is presumed to be sufficient for the "cool" corner, even with turbulent heating considerations. Lowdensity effects also were not included in the calculation of the aeroheating environments. A limited trade study performed as part of this effort showed less then a $2 \%$ impact on the total integrated heat load. This result is attributed to the fact that the low-density effect applies only to the convective heating component, and only at high altitudes. Where convective heating rates are given, they are based on a wall temperature (wall enthalpy) equivalent to radiation equilibrium value at a constant emissivity of 0.8 .

The heating rates are presented as radiative, convective and "total" values. The convective and radiative are "loosely" coupled only in that the radiative heating is allowed to contribute to the increase in wall temperature, thus decreasing the forcing function for the convective heating (enthalpy difference between the recovery and wall 
values). The "total" heating rate is assumed to be the sum of the convective and radiative contributions. No attempt has been made to account for the likely reduction in heating due to coupling between radiation and convection. Ablation and blowing have been ignored. In calculating the heat-transfer rates, the wall temperature was set to the value of the radiation equilibrium temperature at the previous time step. Small calculation intervals were selected so that it was not necessary to iterate at each time step. Cold wall heating rates and loads were also calculated. For the high enthalpy flow conditions such as these (low wall to total enthalpy ratio), the total heat rate approaches the cold wall value. Aeroheating environments were generated only for the portions of the profile below $121,920 \mathrm{~m}$. Aeroheating effects were assumed to be negligible above this altitude.

\section{Direct Earth Entry at Lunar Return Conditions}

Initial conditions for the nominal and off-nominal cases are listed in Table 2. Plots of altitude and acceleration versus earth relative velocity are shown in Figures 5 and 6 , respectively. Of note is the wide variation in acceleration time histories that result from a combination of the initial conditions, ballistic coefficient, and bank angle modulation. Obviously, human rated missions would not be subjected to such loads; however our intent here was to explore the potential reasonable trade space for manned and unmanned flights from a thermal perspective. For manned missions, sustained accelerations below three g's are typically desired.

Figures 7 and 8 illustrate the relative levels of heating at the stagnation and "hot" corner locations for the nominal case. Note that the heating levels for those two regions are quite similar. The radiation equilibrium temperature is included on these figures as a rough indicator of the expected wall temperatures, assuming a non-ablative, insulative TPS. Figures 9 and 10 show the radiation equilibrium temperature and integrated heat load for all 13 lunar direct return trajectories. As evidenced, a wide variation in heating rate, integrated heat load, and wall temperature can be expected depending on the vehicle and entry trajectory characteristics.

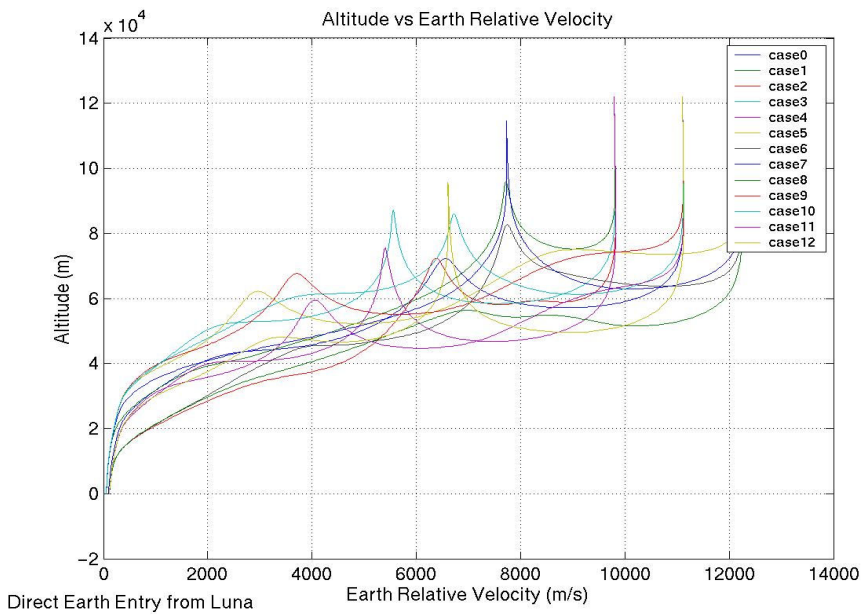

Figure 5. Geodetic altitude versus earth relative velocity for direct Earth entry from Luna cases.

\begin{tabular}{|cccc|}
\hline $\begin{array}{c}\text { Case } \\
\#\end{array}$ & $\begin{array}{c}\text { Initial } \\
\text { velocity } \\
(\mathrm{m} / \mathrm{s})\end{array}$ & $\begin{array}{c}\text { Initial } \\
\text { flight path } \\
\text { angle } \\
(\mathrm{deg})\end{array}$ & $\begin{array}{c}\text { Ballastic } \\
\text { coefficient } \\
(\sim \mathrm{Mach} 30) \\
\left(\mathrm{kg} / \mathrm{m}^{\wedge} 2\right)\end{array}$ \\
\hline 0 & 11075 & -5.80 & 356 \\
1 & 9765 & -3.99 & 122 \\
2 & 9765 & -5.21 & 488 \\
3 & 9765 & -6.65 & 122 \\
4 & 9765 & -7.11 & 488 \\
5 & 12201 & -5.09 & 122 \\
6 & 12201 & -5.61 & 488 \\
7 & 12201 & -6.63 & 122 \\
8 & 12201 & -7.40 & 488 \\
9 & 11075 & -4.63 & 122 \\
10 & 11074 & -6.73 & 122 \\
11 & 11075 & -5.13 & 488 \\
12 & 11075 & -7.29 & 488 \\
\hline
\end{tabular}

Table 2. Initial conditions for lunar direct return trade matrix.

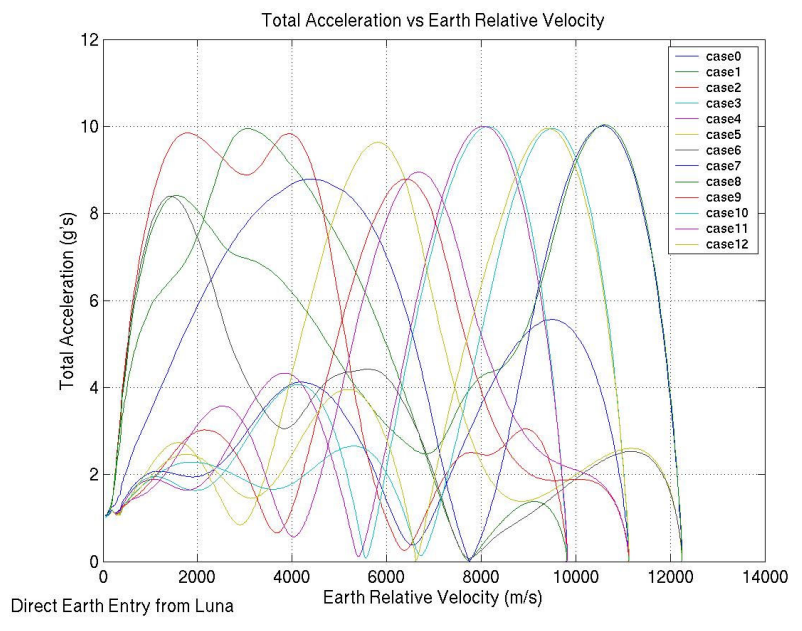

Figure 6. Total sensed acceleration versus earth relative velocity for direct Earth entry from Luna cases. 


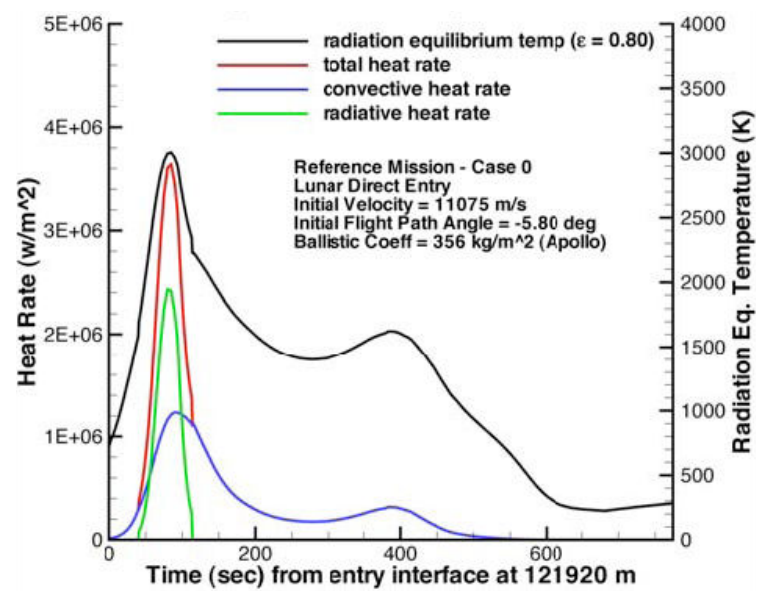

Figure 7. Stagnation area total heating rate buildup for the nominal case with the radiation equilibrium temp.

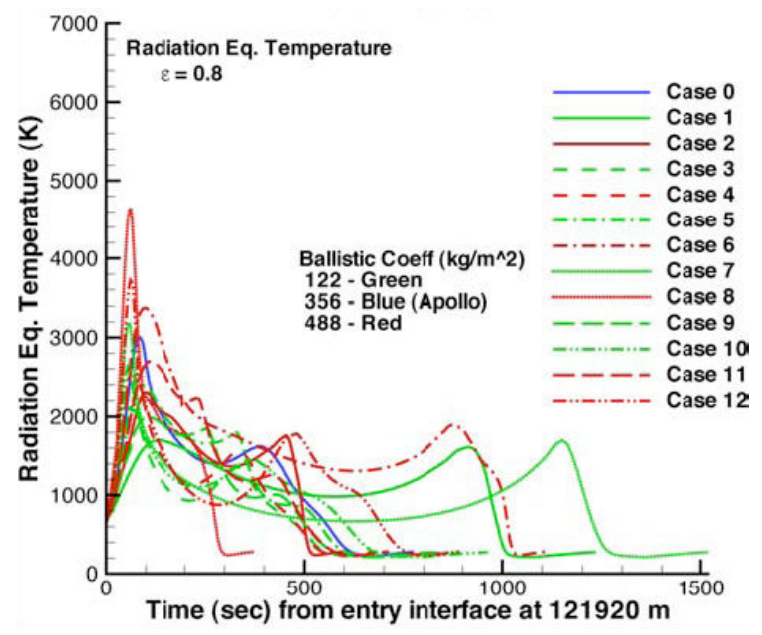

Figure 9. Stagnation region radiation equilibrium temperature for lunar direct return cases.

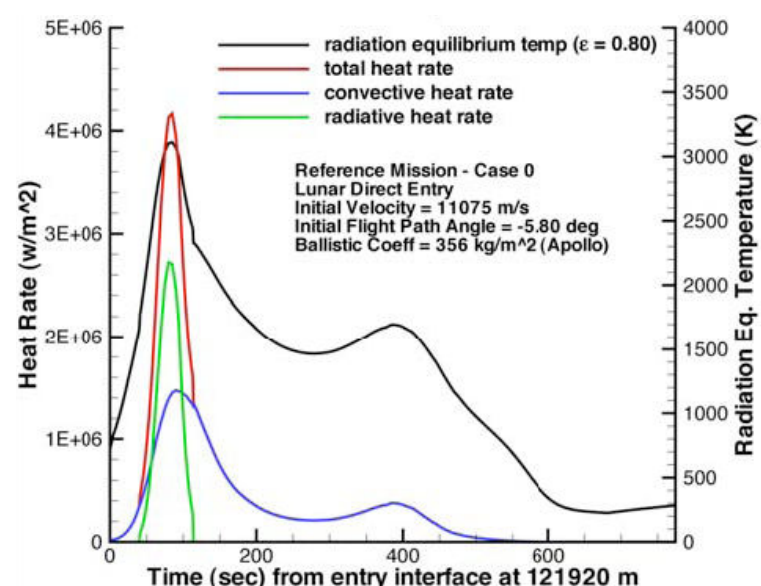

Figure 8. "Hot" corner total heating rate buildup for the nominal case with the radiation equilibrium temp.

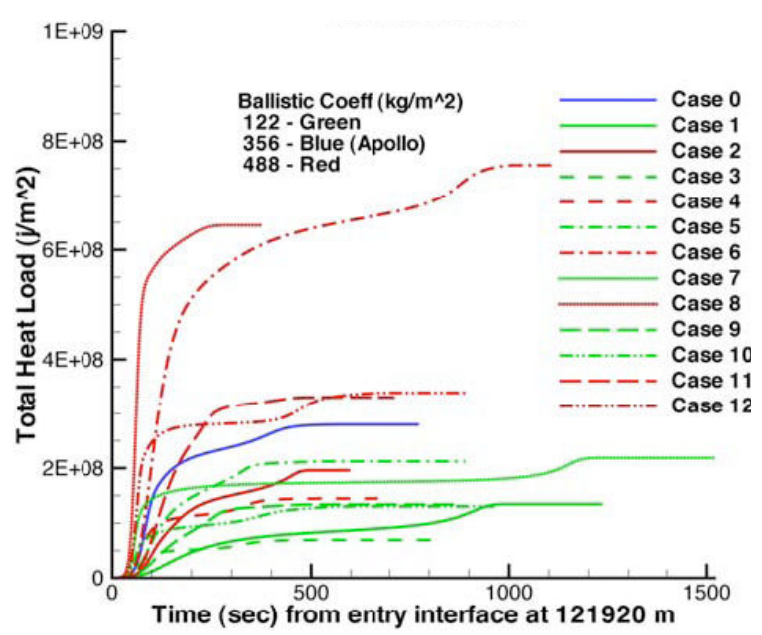

Figure 10. Stagnation region integrated heat load for lunar direct return cases.

\section{Direct Earth Entry at Mars Return Conditions}

Initial conditions for the nominal and off-nominal cases for the direct Earth entry from Mars return conditions are listed in Table 3. The range of initial velocities was selected upon a similar variation in the lunar return velocities. As mentioned, ballistic coefficients were selected to cover a range of potential entry concepts. The original trade matrix consisted of eight cases. Two additional cases at the nominal velocity were added with lower ballistic coefficients for analysis of an aerodynamic decelerator. 
Plots of altitude and acceleration versus earth relative velocity are shown in Figures 11 and 12, respectively. Figures 13 and 14 show the relative levels of heating at the stagnation and "hot" corner locations for the nominal case. Note again that the heating levels for those two regions are quite similar, and that the results here, while similar in nature, are nearly an order of magnitude higher than those for the direct from lunar cases (Figures 7 and 8). Figures 15 and 16 show the radiation equilibrium temperature and total integrated heat load, respectively, for all 11 Mars direct return trajectories. Again, significant increases in both quantities are evidenced when compared to data from the lunar direct return cases.

\begin{tabular}{|cccc|}
\hline $\begin{array}{c}\text { Case } \\
\#\end{array}$ & $\begin{array}{c}\text { Initial } \\
\text { velocity } \\
(\mathrm{m} / \mathrm{s})\end{array}$ & $\begin{array}{c}\text { Initial flight } \\
\text { path angle } \\
(\mathrm{deg})\end{array}$ & $\begin{array}{c}\text { Ballastic } \\
\text { coefficient } \\
(\sim \text { Mach 30) } \\
\left(\mathrm{kg} / \mathrm{m}^{\wedge} 2\right)\end{array}$ \\
\hline 0 & 14008 & -7.20 & 356 \\
1 & 12201 & -5.09 & 122 \\
2 & 12201 & -5.61 & 488 \\
3 & 12201 & -6.63 & 122 \\
4 & 12201 & -7.40 & 488 \\
5 & 16007 & -5.93 & 122 \\
6 & 16007 & -6.53 & 488 \\
7 & 16007 & -6.43 & 122 \\
8 & 16007 & -7.08 & 488 \\
9 & 14008 & -5.58 & 122 \\
10 & 14008 & -5.21 & 49 \\
\hline
\end{tabular}

Table 3. Initial conditions for Mars direct trade matrix.

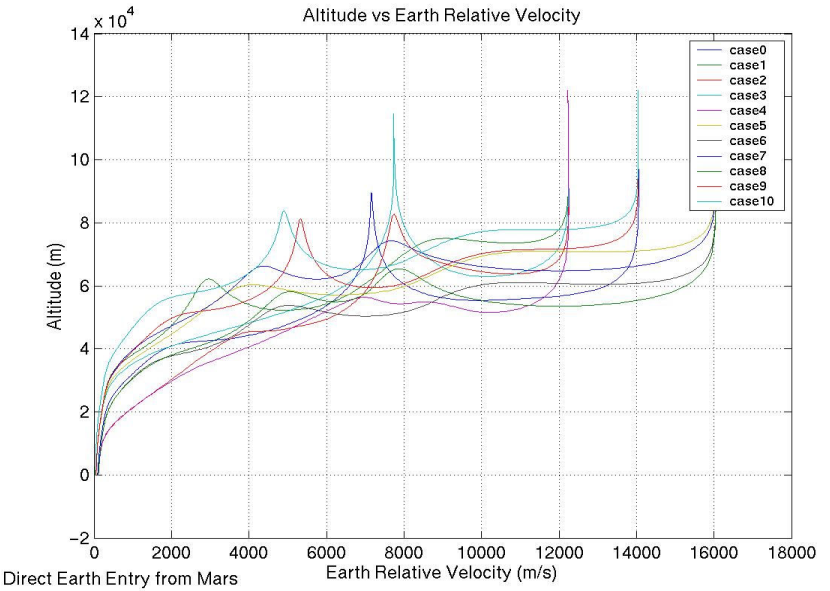

Figure 11. Geodetic altitude versus earth relative velocity for direct Earth entry from Mars cases.

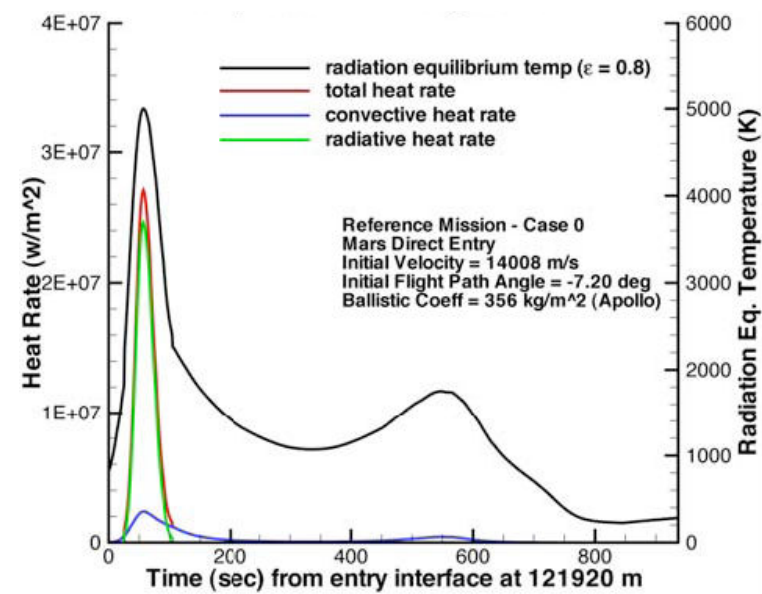

Figure 13. Heating profiles for the stagnation area for the nominal direct Earth entry from Mars case.

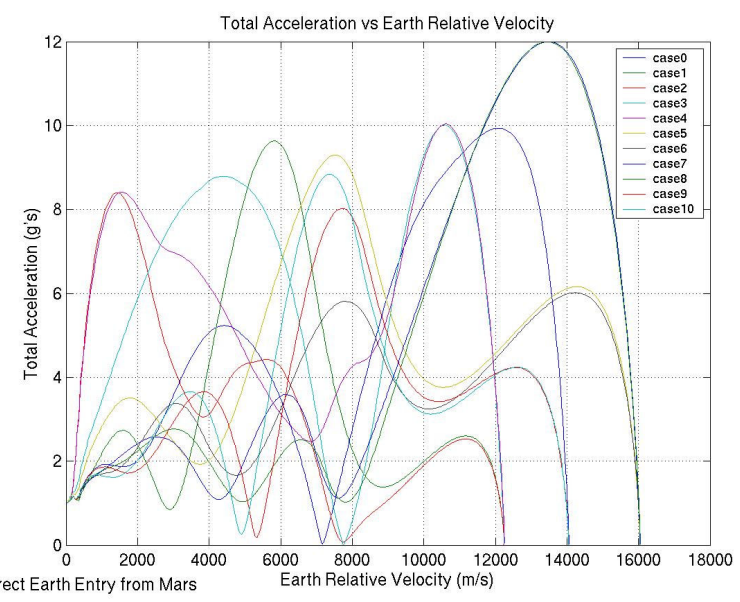

Figure 12. Total sensed acceleration versus earth relative velocity for direct Earth entry from Mars cases.

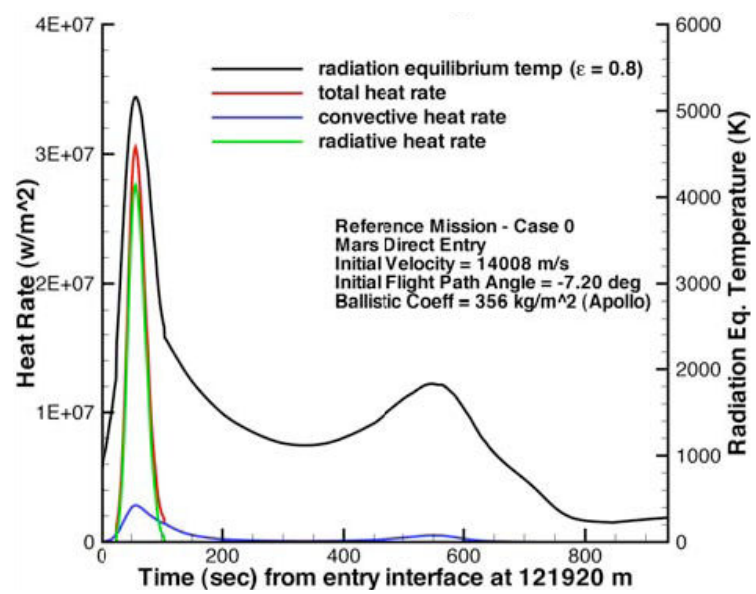

Figure 14. Heating profiles for the "hot" corner for the nominal direct Earth entry from Mars case. 


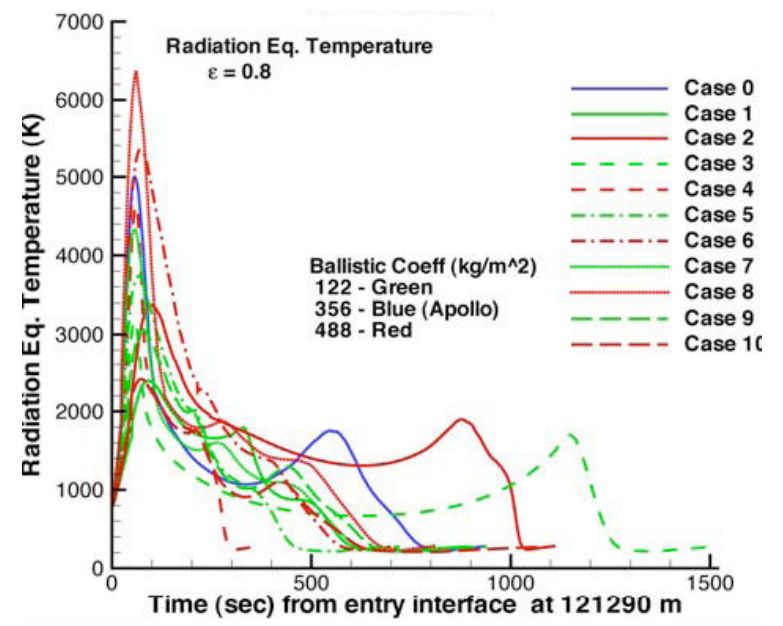

Figure 15. Stagnation region radiation equilibrium temperature for Mars direct return cases.

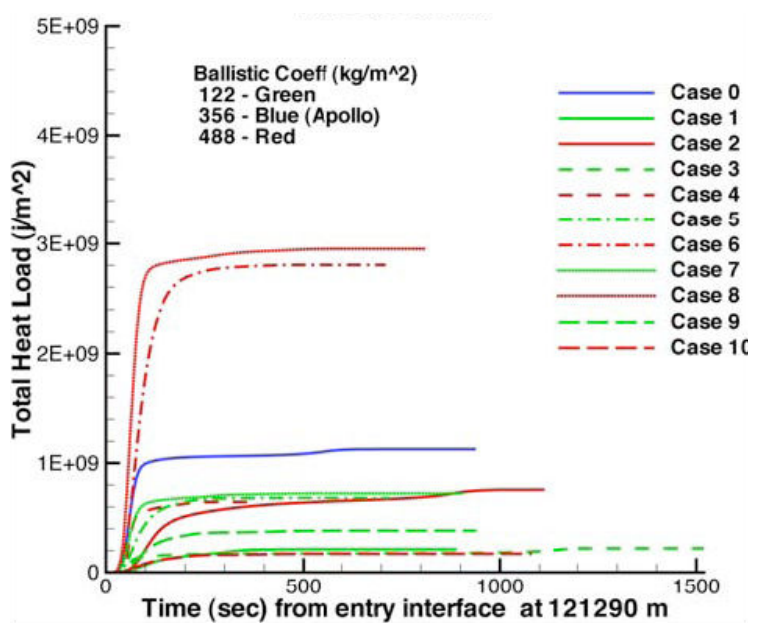

Figure 16. Stagnation region integrated heat load for Mars direct return cases.

\section{Earth Aerocapture from Lunar Return Conditions}

The low, medium and high values of initial velocity and ballistic coefficient used for the Earth aerocapture from lunar return conditions are the same as those selected for the direct lunar entry cases. Initial conditions for the 18 cases (three velocities, three ballistic coefficients, minimum and maximum flight path angle) are listed in Table 4.

Operationally, it is assumed that the vehicle would perform a single pass through Earth's atmosphere (as opposed to aero-braking, i.e. multiple passes) to achieve the desired apogee and would then perform a propulsive burn to raise the perigee to a sustainable orbit. Several events could then occur. The vehicle may wait in orbit for some unknown amount of time until the range is clear or until properly aligned with the landing site and then re-enter. The vehicle could rendezvous and dock with a separate system already in orbit. If this were a manned mission, it is possible that the crew could transfer into the other system for reentry from orbit and return to Earth's surface in which case the original system would remain in orbit and not re-enter. So, only in some scenarios would the original system re-enter from Earth orbit. In the event that it does re-enter, three additional trajectory cases were generated for an Earth re-entry from a $500 \mathrm{~km}$ circular orbit (after performing a de-orbit burn), one each for the high, medium and low ballistic coefficients. To model the entire aerocapture, entry and landing sequence, the heating information for the re-entry from LEO cases should be appended to the appropriate aerocapture case.

For the aerocapture portions, plots of altitude and acceleration versus earth relative velocity are shown in Figures 17 and 18, respectively. As seen, these cases are much better behaved compared to the direct entry cases, 
primarily due to the fact that no steering (bank angle modulation) was implemented in the aerocapture cases. This lack of steering, however, does contribute to higher accelerations for the higher entry velocities. This is even more evident for the aerocapture from Mars cases discussed in the next section. It should be noted that with steering, there would basically be an infinite number of trajectories for each combination of ballistic coefficient and entry velocity that exist between the min and max flight path angles shown in Table 4, and thus peak acceleration loads could be mitigated fairly easily. Figures 19 and 20 show the relative levels of heating at the stagnation and "hot" corner locations for the nominal case. Again, note that the heating levels for those two regions are similar in nature, though the "hot" corner experiences about 20\% higher heating rates. Figures 21 and 22 show the radiation equilibrium temperature and integrated heat loads for all 18 Earth aerocapture from lunar return cases

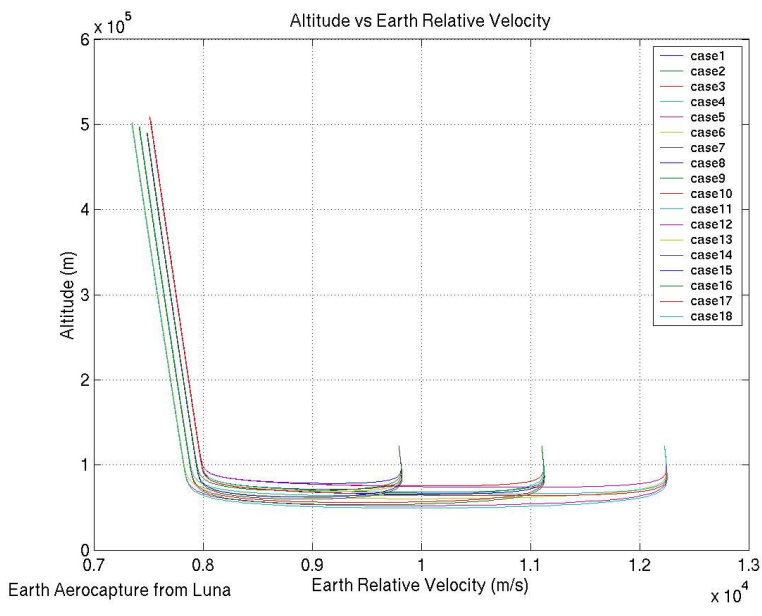

Figure 17. Geodetic altitude versus earth relative velocity for Earth aerocapture from Luna cases.

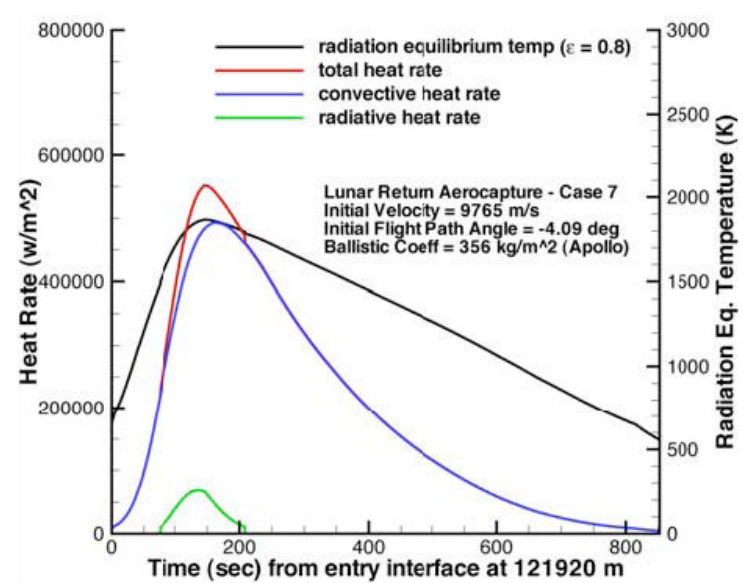

Figure 19. Heating profiles for the stagnation area for Earth aerocapture from Luna case 7.

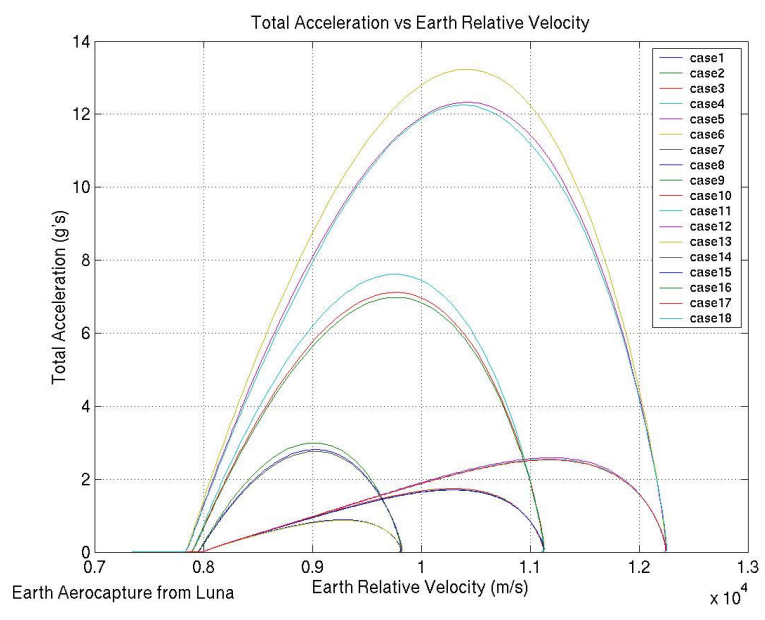

Figure 18. Total sensed acceleration versus earth relative velocity for Earth aerocapture from Luna cases.

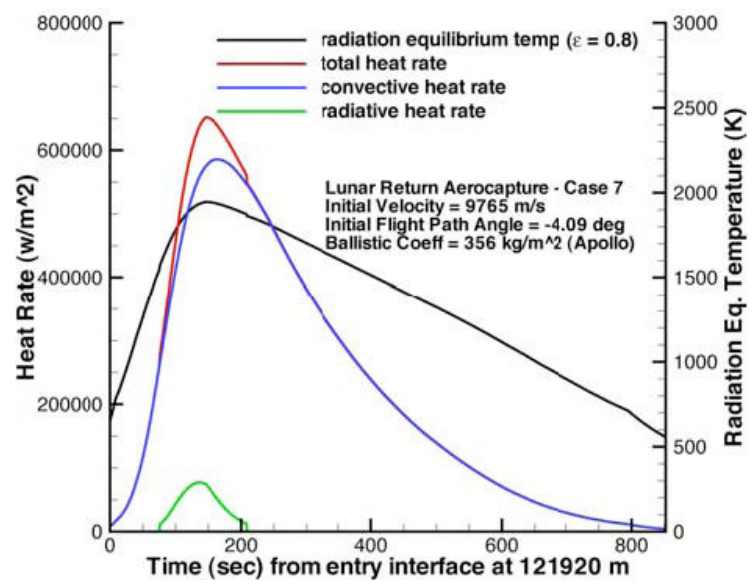

Figure 20. Heating profiles for the "hot" corner for Earth aerocapture from Luna case 7. 


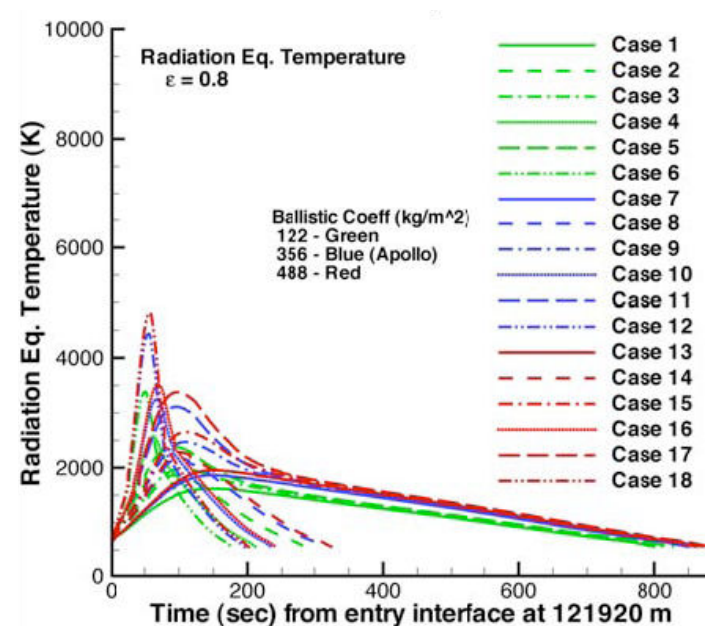

Figure 21. Radiation equilibrium temperatures for the stagnation region for the Earth aerocapture from Luna cases.

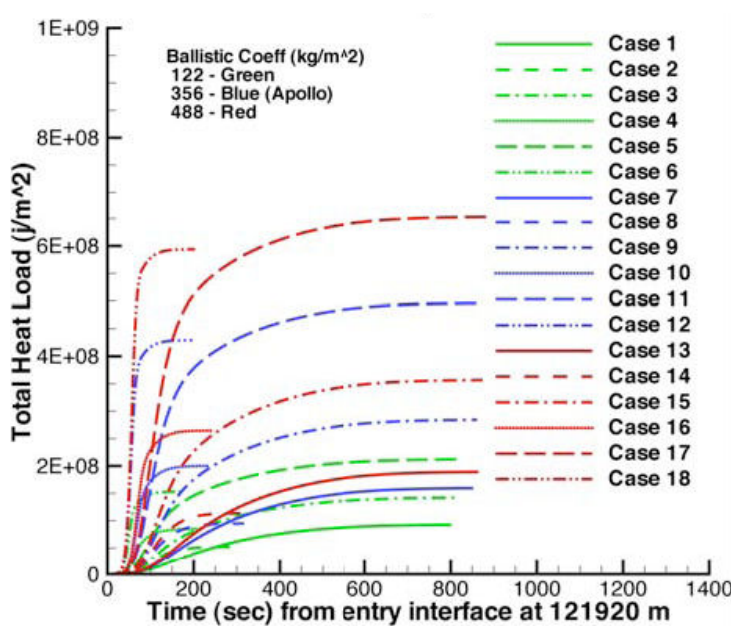

Figure 22. Total integrated heat loads for the stagnation region for the Earth aerocapture from Luna cases.

\section{Earth Aerocapture from Mars Return Conditions}

The low, medium and high values of initial velocity and ballistic coefficient used for the Earth aerocapture from Mars return conditions are the same as those selected for the direct entry from Mars cases. Initial conditions for the 18 cases (three velocities, three ballistic coefficients, min. and max. flight path angle) are listed in Table 5.

Plots of altitude and acceleration versus earth relative velocity are shown in Figures 23 and 24, respectively. Figures 25 and 26 show heating rate profiles for case 1 for the stagnation region and "hot" corner, respectively. Note again that the "hot" corner sees about $15 \%$ more heating. Figure 27 shows stagnation region heating for case 5 , which has the same ballistic coefficient as case 1 but is at the high entry velocity (versus the low velocity for case 1). Notice that the peak total heating rate is more than 5.5 times higher for case 5 , due almost entirely to the radiative heating component. Figures 28 and 29 show the radiation equilibrium temperature and integrated heat loads for all 18 Earth aerocapture from Mars return cases.

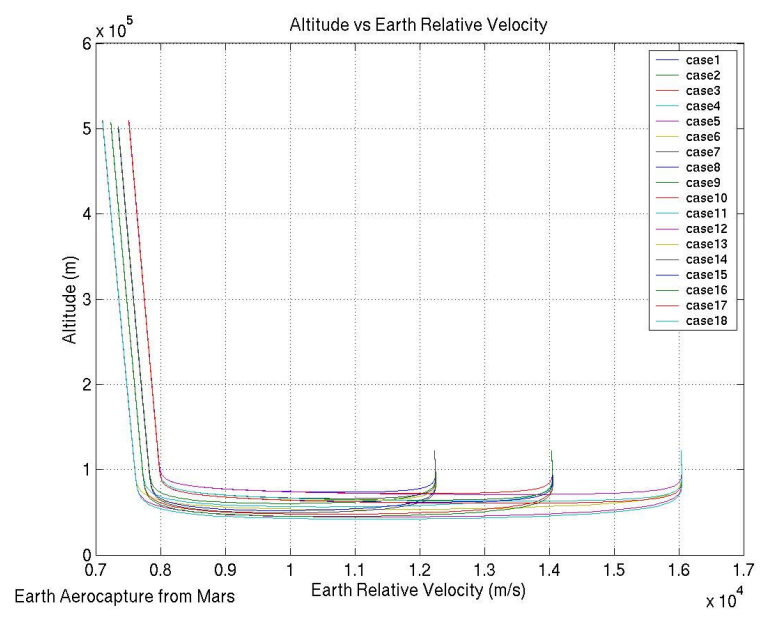

Figure 23. Geodetic altitude versus earth relative velocity for earth aerocapture from Mars cases.

\begin{tabular}{|cccc|}
\hline $\begin{array}{c}\text { Case } \\
\#\end{array}$ & $\begin{array}{c}\text { Initial } \\
\text { velocity } \\
(\mathrm{m} / \mathrm{s})\end{array}$ & $\begin{array}{c}\text { Initial } \\
\text { flight path } \\
\text { angle } \\
(\mathrm{deg})\end{array}$ & $\begin{array}{c}\text { Ballastic } \\
\text { coefficient } \\
(\sim \text { Mach } 30) \\
\left(\mathrm{kg} / \mathrm{m}^{\wedge} 2\right)\end{array}$ \\
\hline 1 & 12201 & -5.09 & 122 \\
2 & 12201 & -7.29 & 122 \\
3 & 14008 & -5.58 & 122 \\
4 & 14008 & -8.63 & 122 \\
5 & 16007 & -5.93 & 122 \\
6 & 16007 & -9.86 & 122 \\
7 & 12201 & -5.49 & 356 \\
8 & 12201 & -7.64 & 356 \\
9 & 14008 & -6.02 & 356 \\
10 & 14008 & -8.98 & 356 \\
11 & 16007 & -6.39 & 356 \\
12 & 16007 & -10.18 & 356 \\
13 & 12201 & -5.61 & 488 \\
14 & 12201 & -7.74 & 488 \\
15 & 14008 & -6.15 & 488 \\
16 & 14008 & -9.07 & 488 \\
17 & 16007 & -6.53 & 488 \\
18 & 16007 & -10.27 & 488 \\
\hline
\end{tabular}

Table 5. Initial conditions trade matrix for Earth aerocapture from Mars return conditions. 


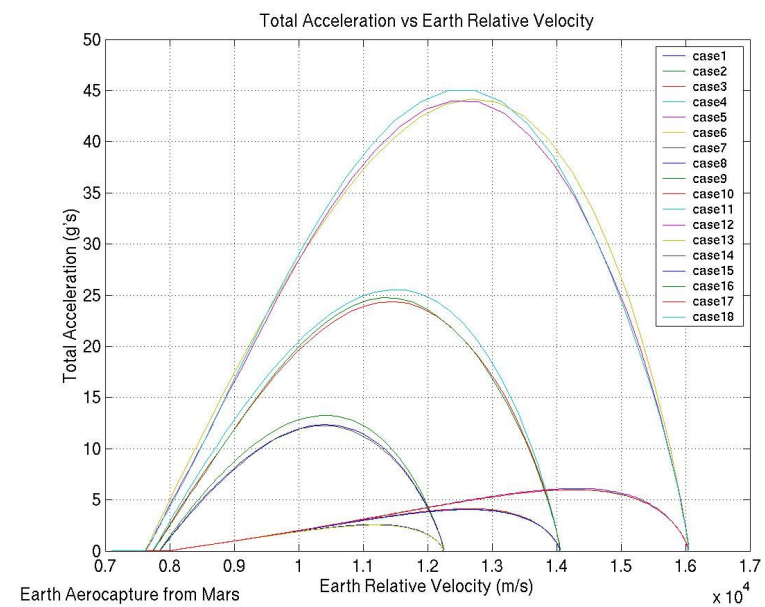

Figure 24. Total sensed acceleration versus earth relative velocity for earth aerocapture from Mars cases.

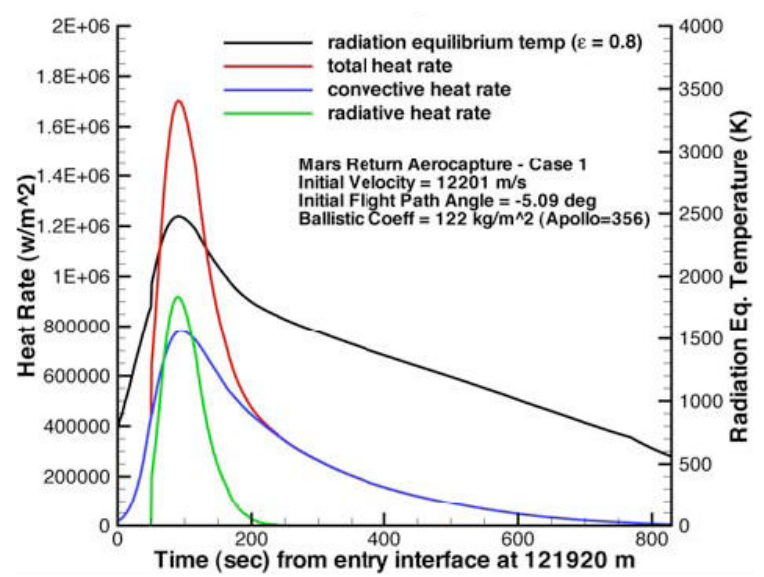

Figure 26. Heating profiles for the "hot" corner for Earth aerocapture from Mars case 1.

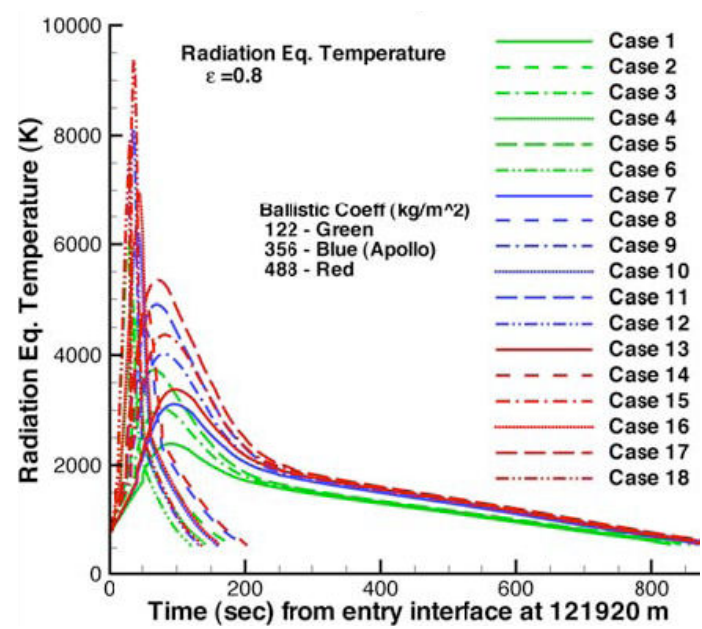

Figure 28. Radiation equilibrium temperatures for the stagnation region for the Earth aerocapture from Mars cases.

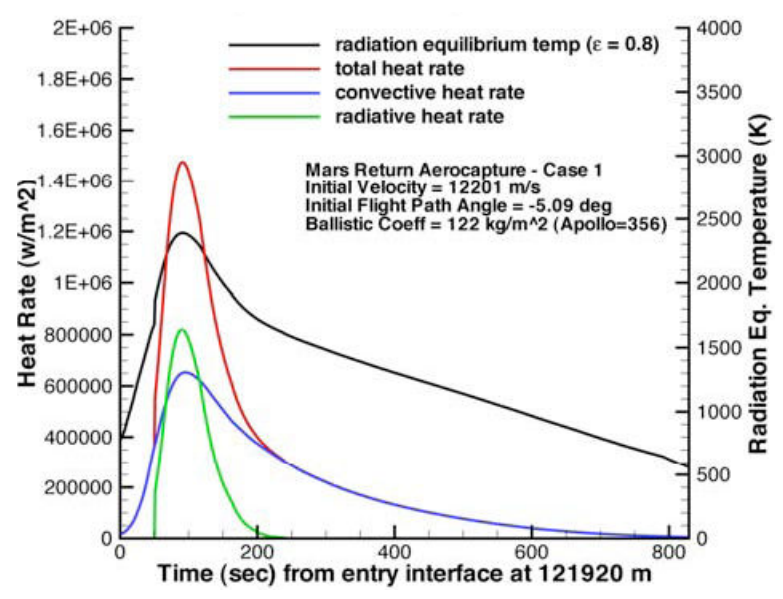

Figure 25. Heating profiles for the stagnation area for Earth aerocapture from Mars case 1.

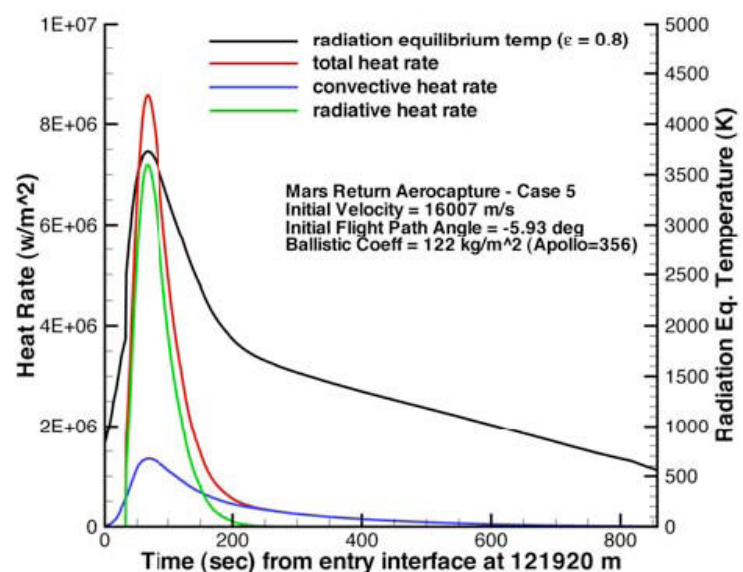

Figure 27. Heating profiles for the stagnation area for Earth aerocapture from Mars case 5.

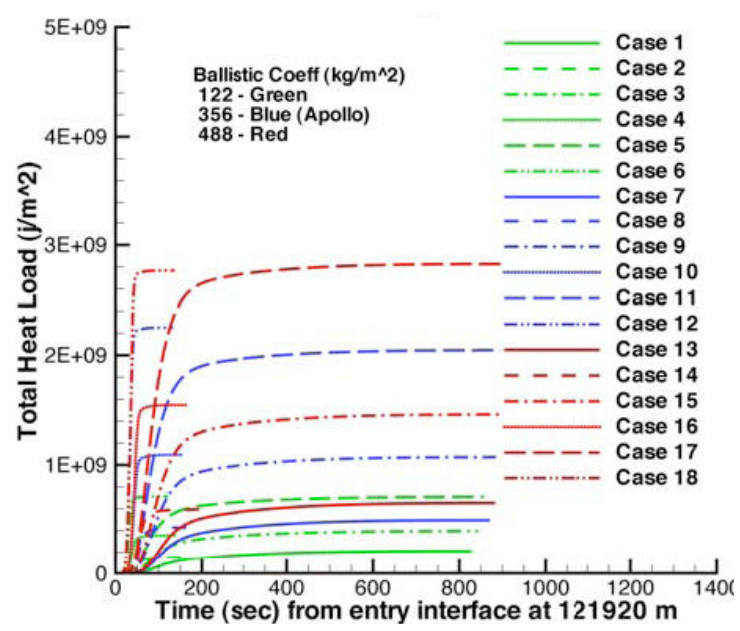

Figure 29. Total integrated heat loads for the stagnation region for the Earth aerocapture from Mars cases. 


\section{Re-Entry from Low Earth Orbit}

As mentioned previously, in some aerocapture scenarios, the vehicle that performs the aerocapture maneuver may also at some point re-enter from low Earth orbit (LEO). For this case, three additional trajectories were generated for an Earth re-entry from a $500 \mathrm{~km}$ circular orbit (after performing a de-orbit burn), one each for the high, medium and low ballistic coefficients. To model the entire aerocapture, entry and landing sequence, the heating information for the re-entry from LEO cases should be appended to the appropriate aerocapture case. An initial entry velocity of $7957 \mathrm{~m} / \mathrm{s}$ and flight path angle of -1.6 deg was assumed for all entries from LEO. This entry mode from LEO also satisfies the crew transport mission to and from the International Space Station, subsequent to the Space Shuttle orbiter retirement.

Figure 30 shows the altitude versus velocity profiles for the three LEO entry cases, along with data from STS28. Figures 31 and 32 show the radiation equilibrium temperature and integrated heat loads for the entry from LEO cases.

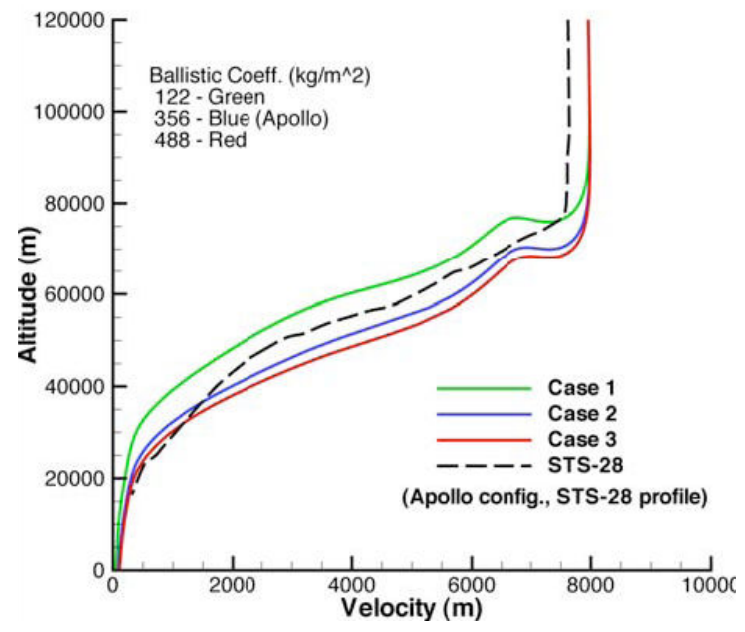

Figure 30. Geodetic altitude versus earth relative velocity for re-entry from low Earth orbit.

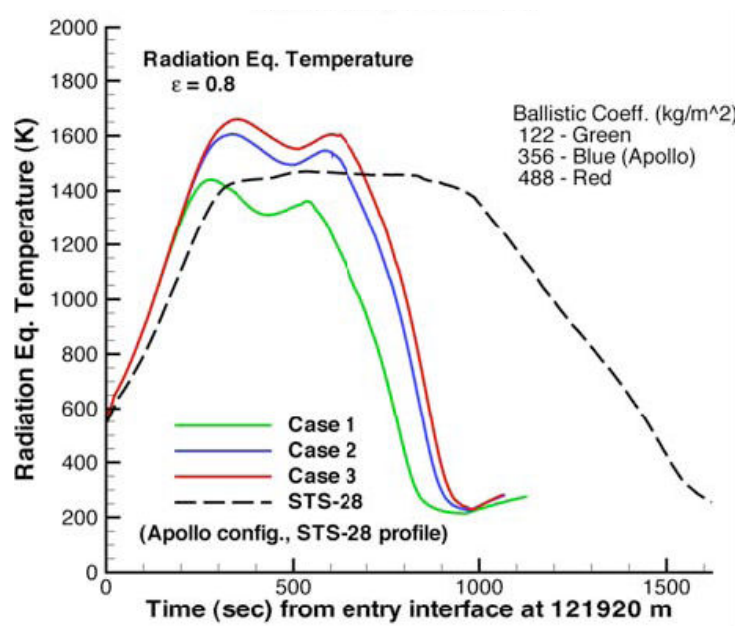

Figure 31. Radiation equilibrium temperatures for the stagnation region for re-entry from low Earth orbit cases.

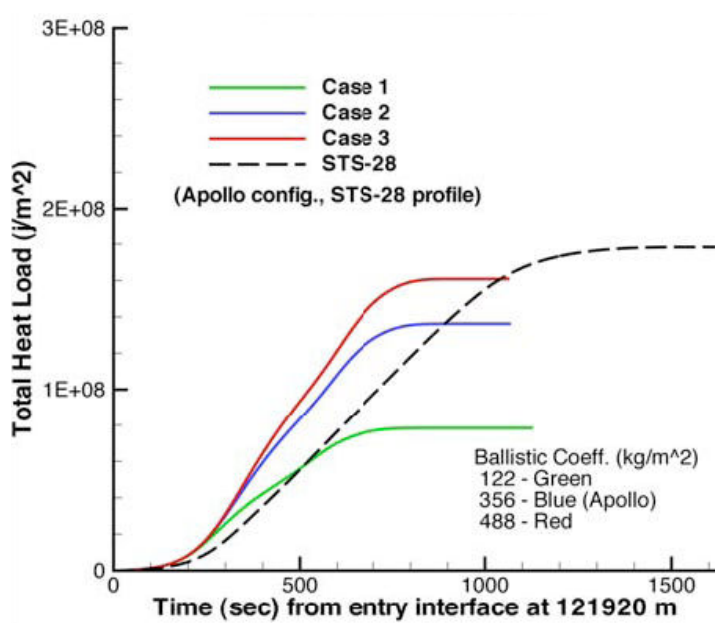

Figure 32. Total heat loads for the stagnation region for re-entry from low Earth orbit cases.

\section{Conclusion}

In summary, more than 60 unique entry trajectories and associated aeroheating environment information were generated in support of two ESR\&T high temperature material and TPS tasks. Using the Apollo Command Module as the baseline entry system, trajectories and aerothermal environments for a range of lunar and Mars return, direct and aerocapture Earth-entry scenarios were developed. The range of trajectories and environments that were generated were intended to bound the wide range of entry scenarios, vehicle characteristics, and TPS requirements for likely CEV concepts. The trades examined clearly pointed to a range of missions / concepts that will require ablative systems as well as a range for which reusable systems may be feasible. As evidenced by the levels of aerodynamic heating and radiation equilibrium temperature, all of the entry cases from Mars return conditions will require ablative TPS, as will the majority of the Lunar return cases. Only the LEO entry cases and the lowest velocity and low ballistic coefficient lunar return cases appear viable for reusable TPS. In addition, the results clearly indicated those entry conditions and modes suitable for manned flight, considering vehicle deceleration levels experienced during entry, though many suitable trajectories exist between the edges of the design space 
explored here. In addition, work currently is underway within several NASA projects to improve the modeling capability for the coupled radiative / convective calculation.

\section{References}

1 “The Vision for Space Exploration,” National Aeronautics and Space Administration (NASA), Feb. 2004.

2 “Apollo Master Spacecraft Specification: Exhibit I, Paragraph 4.2," North American Aviation, Inc., NAS 9-150, Oct. 31, 1963.

${ }^{3}$ Striepe, S.A., Powell, R.W., Desai, P.N., Queen, E.M., Brauer, G.L., Cornick, D.E., Olson, D.W., Petersen, F.M., Stevenson, R., Engel, M.C., Marsh, S.M., and Gromoko, A.M., "Program to Optimize Simulated Trajectories (POST II), Vol. II Utilization Manual." Version 1.1.6.G, January 2004, NASA Langley Research Center, Hampton, VA.

${ }^{4}$ Graves, C. A. and Harpold, J. C., “Apollo Experience Report - Mission Planning for Apollo Entry,” NASA TN D6725, Mar. 1972.

${ }^{5}$ Orloff, R. W., “Apollo By the Numbers: A Statistical Reference for the Manned Phase of Project Apollo," NASA SP-2000-4029, 2000; revised September 2004.

${ }^{6}$ Engel, C. D., and Praharaj, S. C., "MINIVER Upgrade for the AVID System, Vol. I: LANMIN User's Manual," NASA CR-172212, 1983.

${ }^{7}$ Fay, J. A., and Riddell, F. R., "Theory of Stagnation-Point Heat Transfer in Dissociated Air,” Journal of Aeronautical Sciences, Vol. 25, No. 2, 1958, pp. 73-85.

${ }^{8}$ Tauber, M.E. and Sutton, K., "Stagnation-Point Radiative Heating Relations for Earth and Mars Entries," Journal of Spacecraft and Rockets, Vol. 28, 1991, No. 1, pp. 40-42.

${ }^{9}$ Zoby, E.V. and Sullivan, E.M., Effects of Corner Radius on Stagnation-Point Velocity Gradients on Blunt Axisymmetric Bodies. NASA TM X-1067, March 1965.

${ }^{10}$ Ried, R.C, Jr., Rochelle, W.C., and Milhoan, J.D., Radiative Heating to the Apollo Command Module: Engineering Prediction and Flight Measurement. NASA TM X-58091, April 1972. 